\title{
Correction to: Enforcing fine-grained access control for secure collaborative modelling using bidirectional transformations
}

\author{
Csaba Debreceni ${ }^{1,2}\left[\right.$ (]) Gábor Bergmann ${ }^{1,2} \cdot$ István Ráth $^{1} \cdot$ Dániel Varró ${ }^{1,2,3}$
}

Published online: 5 January 2018

○) Springer-Verlag GmbH Germany, part of Springer Nature 2018

\section{Correction to: Softw Syst Model https://doi.org/10.1007/s10270-017-0631-8}

The article "Enforcing fine-grained access control for secure collaborative modelling using bidirectional transformations", written by Csaba Debreceni, Gábor Bergmann, István Ráth, Dániel Varró, was originally published electronically on the publisher's internet portal (https://link.springer.com/journal/ 10270) on [11/21/2017 6:24:42 AM] without open access.

With the author(s)' decision to opt for Open Choice the copyright of the article changed on [date the updated version will be/was published] to (C) The Author(s) [2017] and the article is forthwith distributed under the terms of the Creative Commons Attribution 4.0 International License (http:// creativecommons.org/licenses/by/4.0/), which permits use, duplication, adaptation, distribution and reproduction in any medium or format, as long as you give appropriate credit to the original author(s) and the source, provide a link to the Creative Commons license and indicate if changes were made.
The original article was corrected.

The original article can be found online at https://doi.org/10.1007/ s10270-017-0631-8.

Csaba Debreceni

debreceni@mit.bme.hu

Gábor Bergmann

bergmann@mit.bme.hu

István Ráth

rath@mit.bme.hu

Dániel Varró

varro@mit.bme.hu

1 Department of Measurement and Information Systems, Budapest University of Technology and Economics, Magyar tudósok krt. 2, Budapest 1117, Hungary

2 MTA-BME Lendület Research Group on Cyber-Physical Systems, Budapest, Hungary

3 Department of Electrical and Computer Engineering, McGill University, Montreal, Canada 